\title{
PREPARATION OF ACTIVATED CARBON-ZEOLITE COMPOSITES FROM RICE HUSK ASH
}

\author{
Miyuki Miyazaki and Takeshi Shiono \\ Kyoto Institute of Technology, Kyoto, Japan, \\ Tel: +81-75-721-7577, e-mail: miyazaki.m.kit@gmail.com, shiono@kit.ac.jp
}

Received Date: September 30, 2019; Revised Date: August 13, 2020; Acceptance Date: August 13, 2020

\begin{abstract}
Rice husk (RH) is a biomass resource that contains about 20 mass\% silica. In Southeast Asia countries, RH is used as fuel for thermal power plants, and it produces a large amount of ash (Rice Husk Ash: RHA), as industrial waste. Furthermore, our research group has reported that consolidated zeolite A could be prepared from RHA as a raw material. Zeolite A has hydrophilic micropore in the structure and is used for adsorption and a builder for detergent. From processing point of view, the remaining carbon must be removed before synthesizing of zeolite A. However, the utility of carbon in RHA has not been studied sufficiently. In the present study, therefore, the possibility of usage of both silica and carbon in RHA as a raw material was investigated for the high value-added application of RHA. Before the synthesis of zeolite, activation treatment of carbon was carried out for RHA under specific conditions to make the carbon become porous. The specific surface area was measured by BET for activated RHA. Additionally, hydrothermal treatments were attempted after adjusting the composition of raw materials for the preparation of composites of carbon and zeolite. For the obtained specimens, XRD analysis and SEM were conducted as characterizations to confirm crystalline phases and microstructures respectively. Activation treatment made the specific surface area of RHA larger. As the activation time and temperature increased, silica was crystallized to cristobalite and the reactivity was decreased. The crystalline phase of zeolite A was recognized in the specimens with an appropriate composition. Furthermore, the homogenous zeolite A particles with a size smaller than $1 \mu \mathrm{m}$ were also observed. Therefore, activated carbon-zeolite composites could be synthesized from RHA.
\end{abstract}

Keywords: Activation, Activated carbon, Rice husk ash (RHA), Zeolite A

\section{Introduction}

In recent years, environmental problems such as global warming and abnormal weather have become serious, and there is a movement to reduce carbon dioxide emission. Among them, biomass is one of the renewable energy resources and carbon neutral, so it is expected to contribute to the establishment of a society based on recycling, reusing and reducing, and the suppression of global warming through the expansion of its use [1]. Rice husk is a by-product of rice production, and is also used as fuel for thermal power generations mainly in Asian countries [2]. In using it as fuel, a large amount of rice husk ash is discharged as industrial waste. As biomass power generation becomes popular, an increase in rice husk ash is anticipated. Rice husk is composed of about 80 mass \% of organic compounds, impurities from soil, and about 20 mass\% of silica, which are attributed to the ability of gramineous plants to selectively absorb silica in soil[3]. Rice husk ash has a high content of silica and can be expected to be used as a Si source. In our research group, we have reported the synthesis of consolidated zeolite from rice husk ash as Si source [4]. Zeolite 
is one of functional materials with fine pores of molecular size in a crystalline structure and has properties such as adsorption and ion exchange capacity [5].However, it is necessary to remove the remaining carbon during the synthesis process. The composition of rice husk ash after combustion varies depending on the operating conditions (time, temperature, and atmosphere) of the thermal power plant, and a large amount of carbon may remain. In the present study, an attempt has been made to synthesize carbon-zeolite composites for high value-added application using both carbon and silica in rice husk ash. The carbon in rice husk ash was converted to activated carbon, and zeolite was synthesized using silica in rice husk ash after activation.

\section{Experimental Procedure}

\section{Activation of Carbon in RHA}

Rice husk ash (RHA) discharged from a thermal power plant in Vietnam was used as a raw material. It is known that carbon reacts with carbon dioxide to form micropores as shown in Formula (1) and the reaction proceeds above $850^{\circ} \mathrm{C}[6]$.

$$
\mathrm{Cn}+\mathrm{CO} 2=\mathrm{Cn}-1+2 \mathrm{CO}-172 \mathrm{kcal}
$$

In activation process, $3 \mathrm{~g}$ of RHA and $3.5 \mathrm{~g}$ of rice husk were divided into a closed crucible. Then, the crucible was heat-treated at 850 or $900^{\circ} \mathrm{C}$ from 30 to 120 minutes. Subsequently, RHA after activation was ground for 1 hour with an automatic grinding. For the obtained RHA, the specific surface area was measured by BET (Gemini, SHIMADZU Corp.) between relative pressure 0.01 to 0.10 and the crystalline phases were characterized by XRD (XRay Diffraction, $\mathrm{Cu}-\mathrm{K} \alpha$ radiation, RINT2000 Rigaku Corp., Japan).

\section{Preparation of Activated Carbon-Zeolite Composites}

Zeolite A was synthesized by using Rice husk ash activated for 60 minutes at 850 or $900^{\circ} \mathrm{C}$ as a silicon ( $\mathrm{Si}$ ) source. NaAlO2 (NaAlO2, Wako Corp., Japan) was utilized as sodium (Na) and aluminum $(\mathrm{Al})$ source. $\mathrm{NaAlO} 2$ was weighed so that a molar ratio of $\mathrm{Si}: \mathrm{Al}: \mathrm{Na}$ is 1: 1: 1.23 based on the content of reactive silica in RHA. The reactive silica is described later. Then sodium aluminate, activated RHA and de-ionized water were mixed for making slurry. Subsequently, the slurry was cast into the mold $(1 \times 1 \times 6 \mathrm{~cm})$ and then heat-treated under water vapor atmosphere at $60 \square \mathrm{C}$ for $24 \mathrm{~h}$. For the specimens, XRD analysis and SEM (Scanning Electron Microscope, JSM$7600 \mathrm{~F}$, JEOL Ltd., Japan) were conducted for confirming crystalline phases and microstructure.

\section{Results and Discussion}

\section{Activation of Carbon in RHA}

Table 1 shows the initial composition of RHA. RHA contains about 55 mass\%. In addition, Figure 1 exhibits the thermal analysis results for rice husks and RHA. In rice husk, a remarkable exothermic peak and a weight loss of about 80 mass\% were observed around 300 to $400^{\circ} \mathrm{C}$, resulting from the combustion of organic compounds [7]. Moreover, the combustion temperature of rice husk was lower than RHA. 
Table 1. Chemical Composition of Rice Husk Ash (RHA) in the Present Study

\begin{tabular}{cccrcc}
\hline Sample & Carbon & $\mathbf{S i O}_{2}$ & $\mathbf{K}_{2} \mathbf{O}$ & $\mathbf{C a O}$ & Others* \\
\hline RHA & 54.43 & 41.36 & 2.60 & 0.50 & 1.11 \\
$*$ * $\mathrm{FeO}, \mathrm{MnO}, \mathrm{MgO}$, etc & \multicolumn{3}{c}{ (mass\%) }
\end{tabular}

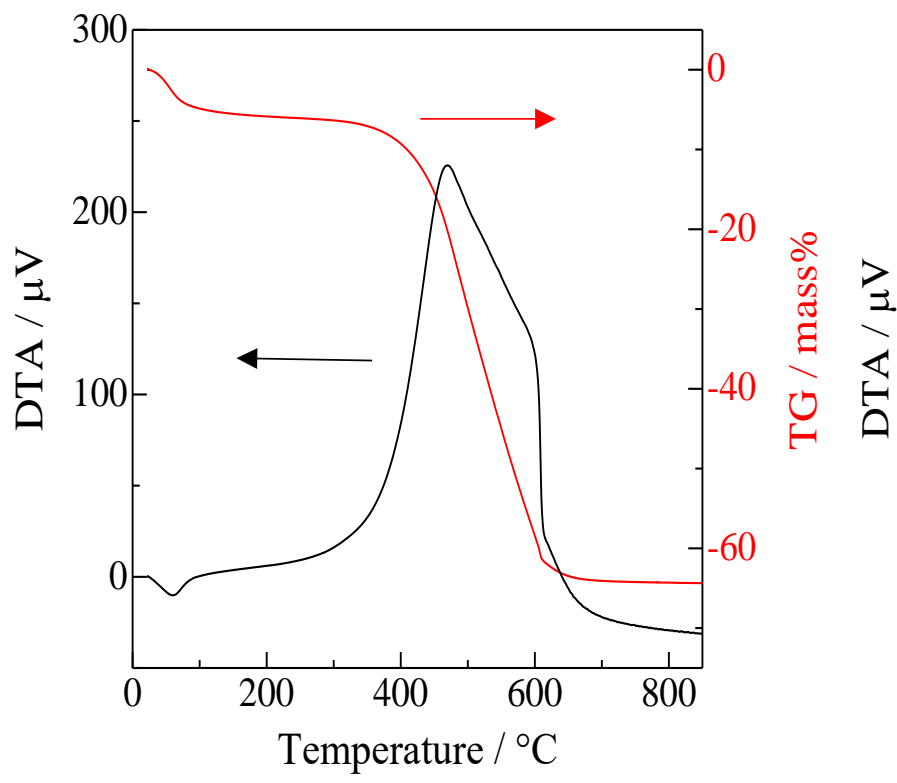

(a)

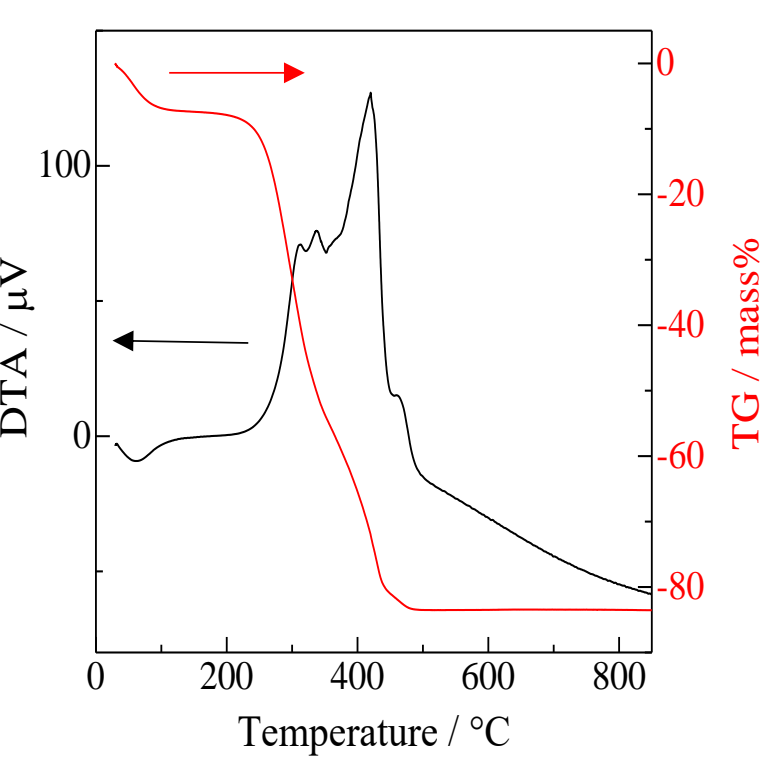

(b)

Figure 1. Thermal analysis of (a) RHA and (b) rice husk

Figure 2 shows the weight loss behaviors of RHA activated at $850^{\circ} \mathrm{C}$ and $900^{\circ} \mathrm{C}$ corresponding to activation time. The weight of activated RHA was heavier than that of RHA without carbon. In other words, activated carbon in RHA did not burn completely. This suggests the following mechanism in the closed crucible. While the rice husk consumed oxygen in the crucible preferentially, it burned and generated carbon dioxide, because the rice husk started to burn at approximately $250^{\circ} \mathrm{C}$. At the temperature at which RHA began to burn, there was not enough oxygen for combustion in the crucible. RHA reacted with carbon dioxide from the rice husk to form micropores as shown in the Formula (1).

As a result, the specific surface area of RHA significantly increased by activation, as shown in Figure 3. The specific surface area of RHA activated for $60 \mathrm{~min}$ is almost the same as that for $30 \mathrm{~min}$, although the weight of RHA activated for $60 \mathrm{~min}$ decreased by approximately 10 $\%$ compared to that for $30 \mathrm{~min}$. However, the area decreased at both temperatures from 60 to 120 minutes. From these results, it can be guessed that as the activation time became longer, the reaction of Formula (1) proceeded and the amount of carbon decreased, leading to a decrease in specific surface area. The XRD analysis patterns of as-received RHA and the RHA activated at $850^{\circ} \mathrm{C}$ are illustrated in Figure 4. As-received RHA originally contained cristobalite as crystalline silica. The peaks were identified by ICDD 27-0605. It was found that the peak intensity increased and the halo decreased with longer heat-treatment. This could be due to the influence of alkaline 
impurities like potassium oxide and calcium oxide. Usually, temperature higher than $1000^{\circ} \mathrm{C}$ is required to transform amorphous silica to cristobalite phase, but it is known that the phase transition temperature decreases in the presence of alkali oxides [8]. It was expected that the amorphous silica was easily transformed into crystalline at $850^{\circ} \mathrm{C}$ by alkaline oxides from soil, and the same tendency was confirmed at $900^{\circ} \mathrm{C}$. Especially in the presence of $\mathrm{K} 2 \mathrm{O}$, silica forms a liquid phase at $742^{\circ} \mathrm{C}$ in the phase diagram [9], so it is possible that the liquid phase covered the micropores of carbon and contributed to the reduction of the specific surface area.

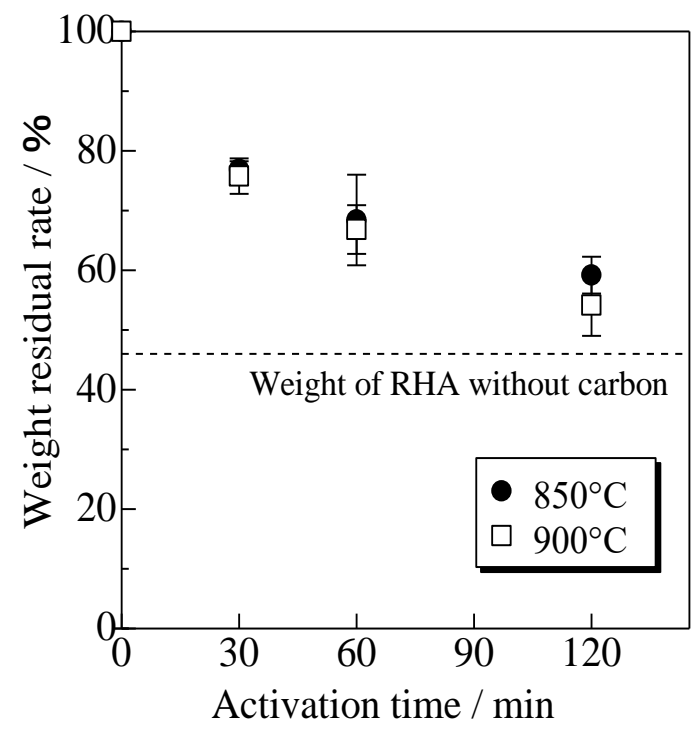

Figure 2. Weight residual rate of RHA activated at 850 and $900^{\circ} \mathrm{C}$

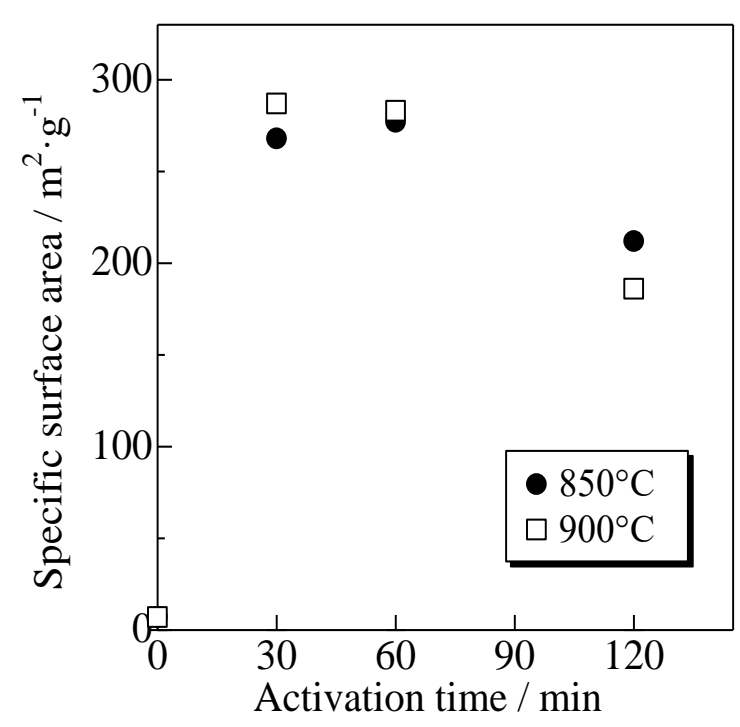

Figure 3. Specific surface area of RHA activated at 850 and $900^{\circ} \mathrm{C}$

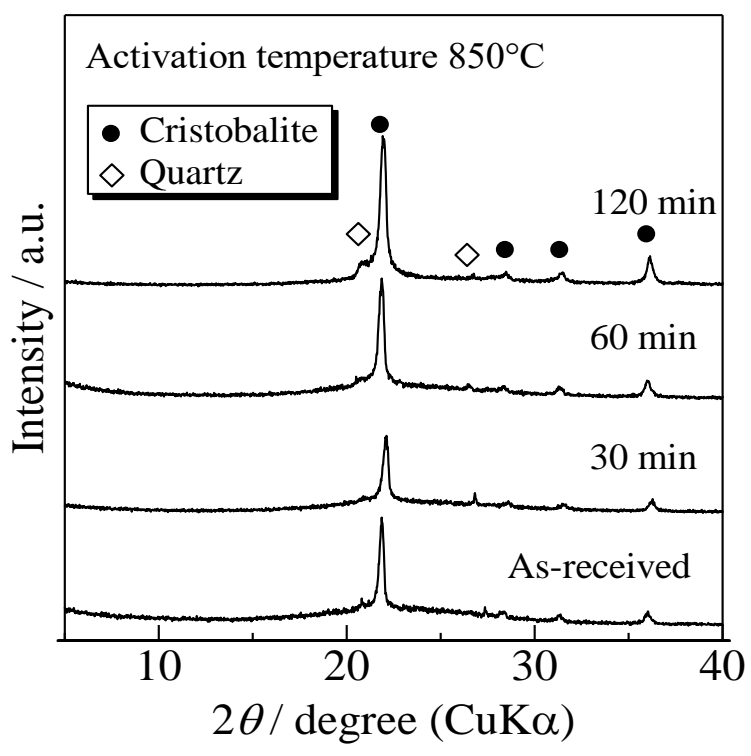

Figure 4. XRD patterns of as-received RHA and RHA activated at $850^{\circ} \mathrm{C}$ 


\section{Preparation of Activated Carbon-Zeolite Composites}

Activation treatment decreases carbon content and relatively increases the amount of silica in activated RHA. When the heat-treatment for activation is carried out for $60 \mathrm{~min}$, the amount of silica in the RHA is about 60 mass\%. However, it is unlikely that all the silica will be used for the reaction of zeolite synthesis because some of the silica is crystallized from figure4. The crystalline phase is stable and will not produce zeolitein the synthesis condition of the present study. Therefore, it was assumed that the amount of reactive silica in activated RHA consumed for zeolite synthesis was 20 to 50 mass\% of the activated RHA. Therefore, A30 means that activated RHA contains 30 mass \% of reactive silica. Figure 5 shows the XRD patterns of RHA activated at $900^{\circ} \mathrm{C}$ for 60 min. In the composition of A20, only cristobalite peaks were recognized, and no zeolite was formed. On the other hand, A30, 40, and 50 had peaks identified with zeolite A. As the amount of sodium aluminate increased, the peak intensity of zeolite A increased compared to that of cristobalite, and the peak of gibbsite, a kind of aluminum hydroxide, was also observed. Therefore, it is considered that enough sodium aluminate was added in the A30 composition to form zeolite. However, the small peak of gibbsite peak was also seen in A30. This is guessed to be due to the slow dissolution of silica and the residual aluminum and sodium. The XRD results of specimens with A30 and A40 compositions using RHA activated at $850^{\circ} \mathrm{C}$ were illustrated in Figure 6 . The formation of zeolite A was observed for both compositions, in the same as the samples prepared with RHA activated at $900{ }^{\circ} \mathrm{C}$.A30 showed almost no gibbsite formation. The peaks of zeolite A and gibbsite were identified by ICDD 39-0222 and 33-0018 respectively.

-Zeolite A $\nabla$ Cristobalite $\Delta$ Gibbsite $\square$ Unknown

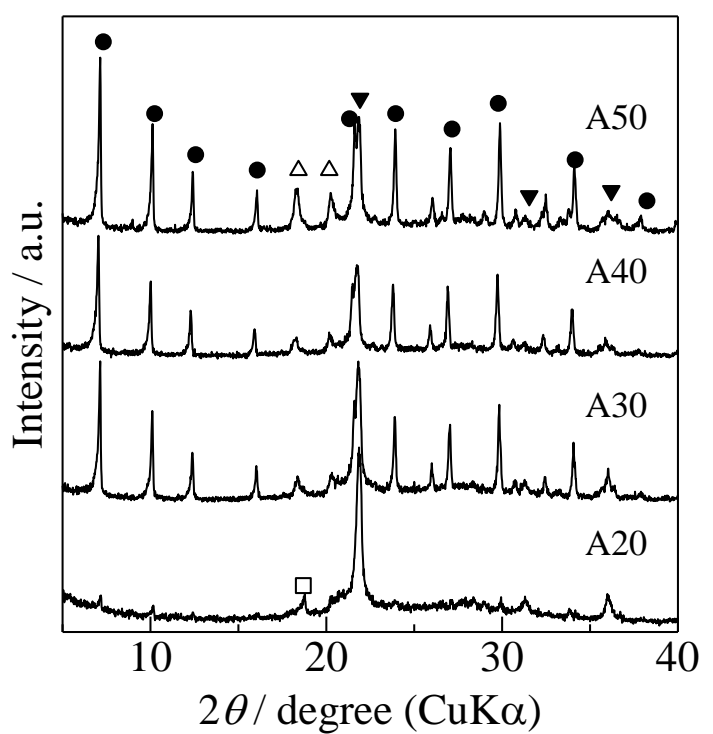

Figure 5. XRD patterns of specimens with each composition using RHA activated at $900^{\circ} \mathrm{C}$

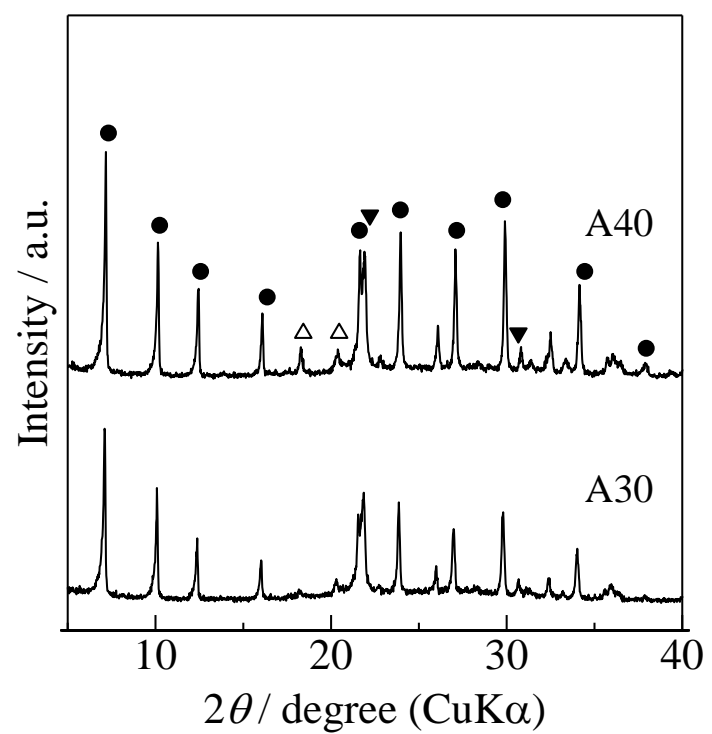

Figure 6. XRD patterns of specimens with each composition using RHA activated at $850^{\circ} \mathrm{C}$ 
The crystallinity of each specimen prepared with RHA activated at both temperatures was listed in Table 2. It was found that even with the same composition, the lower the activation temperature, the higher the crystallinity. From these results, it was suggested that the lower the activation temperature, the better the reactivity of the silica, even if the specific surface areas were almost equal. Figure 7 is the SEM image of A40 prepared with RHA activated at $900^{\circ} \mathrm{C}$. Cubic uniform particles peculiar to zeolite A were observed [5], and the particle size was approximately $1 \mu \mathrm{m}$. This result had good agreement with the XRD analysis results. Furthermore, the EDX results of the same specimen in Figure 7 were shown in Figure 8. From these images, the size of carbon was around 10 to $20 \mu \mathrm{m}$ and coexisted with zeolites. The zeolite particles were deposited around the carbon.

Table 2. The Crystallinity of Each Specimen Activated at Both Temperatures

\begin{tabular}{ccccc}
\hline $\begin{array}{c}\text { Activation temperature } \\
\text { Composition }\end{array}$ & A30 & A00 & \multicolumn{2}{c}{$\mathbf{8 5 0}^{\circ} \mathrm{C}$} \\
Crystallinity /\% & 66.7 & 70.1 & A30 & A40 \\
\hline
\end{tabular}

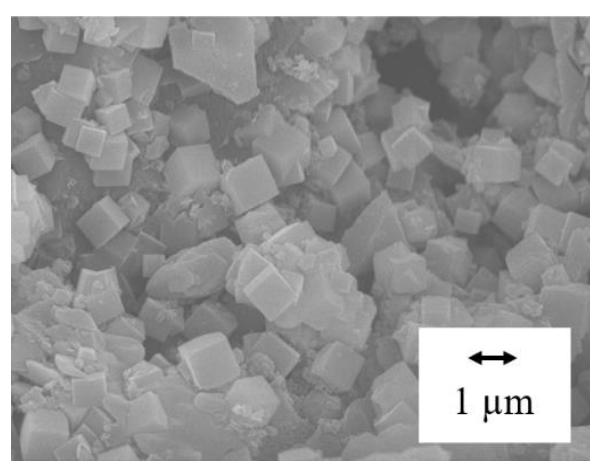

Figure 7. SEM image of A40 using RHA activated at $900^{\circ} \mathrm{C}$

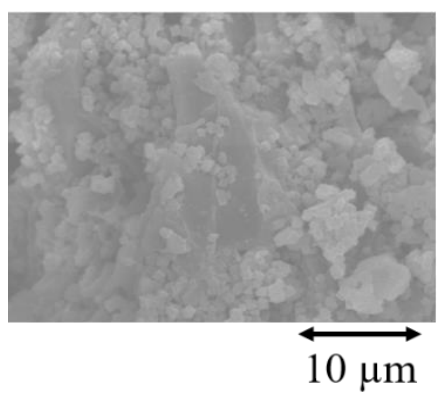

(a)

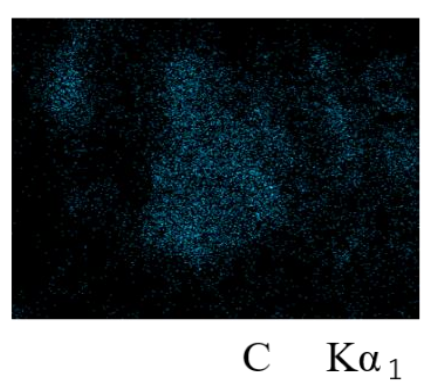

(b)
Figure 8. (a) SEM image and (b) carbon atom mapped EDX result of $\mathrm{A} 40$ using RHA activated at $900^{\circ} \mathrm{C}$

\section{Summary}

Porous materials were tried to be prepared for an effective utilization of components in rice husk ash, silica and carbon. The activated carbon-zeolite composites were prepared by using the activated RHA.

Activation of carbon in RHA increased the specific surface area of RHA by generating micropores in the carbon.

Zeolite A could be obtained (synthesized) by adjusting the composition in consideration of crystallization of some silica. 
The uniform cubic zeolite A particles deposited on carbon particles. The activated carbon-zeolite composites were able to be prepared by using the activated RHA. Therefore, these composites could be expected to utilize as an adsorption of several toxic substances which have different polarities.

\section{References}

[1] K. Sakanishi, "Significance and future perspective of biomass utilization," Material Cycles and Waste Management Research, Vol. 21, No. 1, pp. 18-22, 2010. doi: 10.3985/mcwmr.21.18

[2] R. Pode, "Potential application of rice husk ash waste from rice husk biomass power plant," Renewable and Sustainable Energy Reviews, Vol. 53, pp. 1468-1485, 2016. doi: 10.1016/j.rser.2015.09.051

[3] E. Takahashi, Sakumotsu ni Totte Keisan Toha Nanika (What is Silica for Crops?), Rural Culture Association Japan, Tokyo, Japan, 2007.

[4] K. Marutani, T. Shiono, and Y. Okamoto, "Synthesis of consolidated zeolite from rice husk ash," Journal of the Society of Materials Science, Vol. 62, No. 9, pp. 575-578, 2013. doi: $10.2472 /$ jsms.62.575

[5] H. Tominaga, Zeoraito no Kagaku to Ouyo (Zeolite Science and Technology), Japanese Edition, Koudansha Ltd., Tokyo, Japan, 1987.

[6] I. Abe, "Production methods of activated carbon," TANSO, Vol. 2006, No. 225, pp. 373381, 2006.doi: 10.7209/tanso.2006.373

[7] Y. Nakata, M. Suzuki, T. Okutani, M. Kikuchi, and T. Akiyama, "Preparation and properties of SiO2 from rice hulls," Journal of the Ceramic Society of Japan, Vol. 97, No. 1128, pp. 842-849, 1989.doi: 10.2109/jcersj.97.842

[8] M. Higuchi, and Y. Azuma, "Effect of alkali metal oxide addition on crystallization and phase transformation of sintered spherical silica," Journal of the Ceramic Society of Japan, Vol. 105, No. 1221, pp. 385-390, 1997. doi: 10.2109/jcersj.105.385

[9] R.S. Roth, ed., Phase Equilibria Diagrams: Phase Diagrams for Ceramists:.Oxides, The American Ceramic Society, Westerville, United States, Vol. XIV, 2005. 